http://www.jumdc.com/

Original Article

\title{
Missed dose error among nurses working at tertiary care hospitals, Karachi
}

\author{
Raja $^{\mathrm{a}}$, Badil ${ }^{\mathrm{b}}$, Pawan Kumar ${ }^{\mathrm{c}}$, Sana Rehmand, Gulsher \\ ${ }^{a}$ Staff Nurse, Department of Plastic and Reconstructive Surgery, Pfau Civil Hospital, Karachi. \\ ${ }^{b}$ Director and Associate Professor, Dow Institute of Nursing and Midwifery, Dow University of Health Sciences, Karachi \\ 'Assistant Professor of Medicine, Dow Medical College, Dow University of Health Sciences, Karachi \\ ${ }^{d}$ Lecturer, Pharmacy Practice Department, Faculty of Pharmacy, University of Karachi.

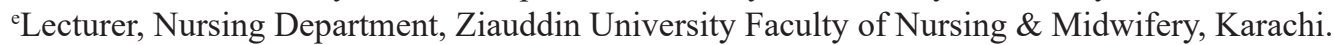 \\ *Corresponding author: rajakhatri33@gmail.com
}

ABSTRACT

BACKGROUND \& OBJECTIVE: Medication administration error (MAE) has been recognized as a serious health related issue that can lead to surge mortality and morbidity. In addition, it may rise hospitalization that will increase the ratio of the patient. This study was accomplished to determine the missed dose error among nurses working at tertiary care hospitals, Karachi.

METHODOLOGY: This analytical cross-sectional study was accomplished at Dr. Ruth K.M. Pfau Civil Hospital and Dow University Hospital, Karachi for the period of six months from February to July 2018. The calculated sample was 204 nurses of both genders. Nurses having one year of working experience and licensed with Pakistan Nursing Council had been invited for the study. The participants were approached by a non-probability convenient sampling method. The adopted and validated questionnaire was utilized to gather the data. The data was entered and analyzed by using SPSS version 21.0.

RESULTS: Out of 204 subjects, $106(52 \%)$ were male. With respect to age, $168(82.3 \%)$ of respondents had age below 35 years. The percentage of missed medication doses was reported to be $12.3 \%$. In this study, nurses to patients ratio, and timing of medication administration were found statistically significant with missed dose errors $p$-value $\leq 0.05$.

CONCLUSION: The study finding showed a small frequency of missed dose errors among nurses working in a tertiary care public sector hospitals, Karachi. The majority of missed doses were recorded in the morning shift, and nurses who had more patients ratio.

KEYWORDS: Missed dose, Nurses, Tertiary Care Hospitals.

\section{INTRODUCTION}

Medication administration error (MAE) is a leading issue in the hospitals all around the globe. There are various types of MAE such as wrong dose, wrong route, wrong time, wrong medicine and administration of medication to the wrong patient. Amongst, a single error may cause unusual harm to the patients. Patient safety is a significant task of healthcare organizations.

Proper medication administration improves the patient's outcome which ultimately leads to the decrease in the length of stay in the hospital and also reduces the cost. On the other hand, missed medication doses increase the risk of mortality and morbidity among hospitalized patients. Proper medication administration and patient's safety is crucial for speedy recovery of the patients ${ }^{[1]}$. The vital role of nurses is to ensure the safety of patient, in spite of the fact that patients are repeatedly harmed due to medication errors by healthcare workers ${ }^{[2]}$.
$12.9 \%$ of missed dose errors documented in Egypt ${ }^{[3]}$. There are certain factors responsible for MAE including overburden, shortage of nurses, limited knowledge, inexperience, interruption while working, nurse-patient ratio, and improper work distribution ${ }^{[4-5]}$. It is affirmed that, one error occurs on hospitalized patients every day ${ }^{[6]}$.

Therefore, the medication administration process should be improved in health care delivery system. Missed dose error has been recognized as the most prevalent medication error globally, which is $42 \%$ and followed by wrong time error. The frequency of medication administration error is 50\% as reported by "National Patient Safety Agency" (NPSA). Moreover, wrong timing of medication administration error has consequences ${ }^{[4]}$. The average of MAEs has been recorded from $9.4 \%$ to $80 \%$ in United kingdom, Middle East and East African countries ${ }^{[7-8]}$. The study conducted in Pakistan revealed $7.5 \%$ of missing doses error, while $17 \%$ wrong time error in a private healthcare setting ${ }^{[6]}$ and $27.45 \%$ in public sectors tertiary care hospital ${ }^{[9]}$. 
Furthermore, another study accomplished in Karachi, Pakistan disclosed $21 \%$ medication error rate ${ }^{[10]}$. Highest prevalence of missed dose error and MAEs i.e 74.4\% and $82.1 \%$ respectively, has been identified in a study [11,12]. Therefore, the current study aimed to determine the missed dose error among nurses working at tertiary care hospitals in Karachi.

\section{METHODOLOGY}

Present analytical cross-sectional study was conducted at two major tertiary care public sector hospitals of Karachi. Registered Nurses having one year and above clinical experience were approached to participate in the study. The study was completed in the duration of six months, from February to July 2018. The sample size was calculated through OpenEpi version 3.0, an online sample size calculator. Calculated sample size was 204 nurses of both genders. It was calculated by taking $56.4 \%$ of MAE ${ }^{[4]}$ with $95 \%$ confidence level and 5\% margin of error.

Convenient non-probability sampling technique was used to approached the participants. Participation of the subjects was voluntary. Firstly, all the nurses were invited to attend the introductory session of the present study. The study was conducted after taking the approval from institutional Review Committee (IRB) from Dow University of Health Sciences Karachi [Ref. No: IRB-968/DUHS/Approval/2017/11]. Moreover, the data collection permission was also granted from the Medical superintendent of both data collection sites. Adopted and validated questionnaire was used to collect data. Permission of the tool was also granted from the primary author. Data was entered and analyzed in SPSS version 21.0. All descriptive data like gender, designation, working area and educational status was computed in frequency and percentage. Chi-square test was applied to determine the association between demographic variables and missed dose error. $\mathrm{p} \leq 0.05$ was considered as significant.

\section{RESULTS}

\section{Demographic information of the study participants:}

In this research study, 204 participants were included. Amongst , 98 (48\%) were female and 106 (52\%) were male. The majority $(43.1 \%)$ of the study participants had age between $25-30$ years old. Only 71 (34.8\%) study participants had a bachelor degree in nursing, while, 133 (65.2\%) had diploma in general nursing. The ratio method was used to collect the data. Hence, the majority $(77 \%)$ of the data was collected from Dr. Ruth K.M Pfau Civil Hospital and rest of participants were taken from Dow University Hospital Karachi. Nearly half (47.5\%) of the study participants had an experience of less than 5 years. Approximately onethird $(34.3 \%)$ of the study nurses administered medication up to 10 patients. Figure-I reveals the frequency of missed drug errors among nurses. In this study, 716 medications were administered by 204 nurses. Amongst, 88 (12.3\%) medication doses had not been administered to the patients. While $628(87.7 \%)$ nurses had administered medication doses as advised by doctors.

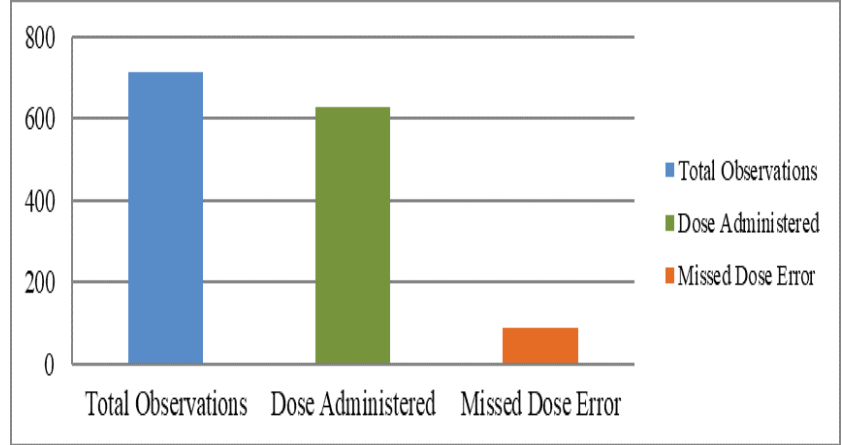

Figure-I: Missed Dose Error.

Figure-II highlights the frequency of missed doses and administered medication doses by individual nurses. It was recorded that almost one-third participants (35.78\%) have had not administered medication as advised. In contrast, at night shift 37 (72.54\%) of the nurses failed to administer patient's medication. While in evening shift only one-fourth $12(27.28 \%)$ nurses had not administered medication to their patients.

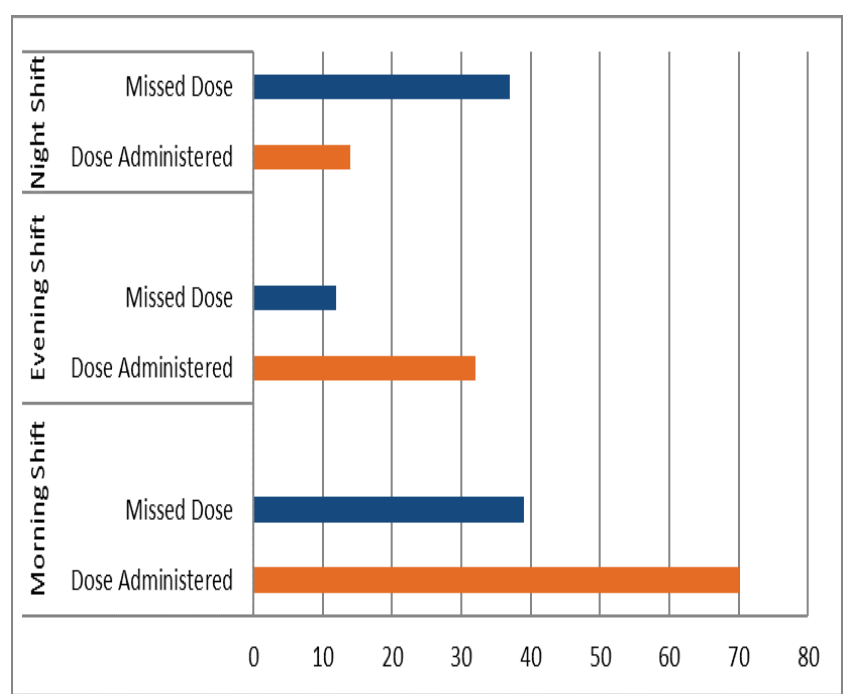

Figure-II: Missed Doses and Doses Administered by Individual Nurses per Shift.

Table-I discloses the association of missed dose errors with socio-demographic characteristics. In present study, no statistical differences were found between age group, gender, experience, and educational status of the participants ( $p$-value $>0.05$ ). With respect to hospital, more missed drug errors were recorded in Dr. Ruth K.M Pfau Civil Hospital as compared to Dow University Hospital Karachi, however, this variable was not statistical significant with missed dose error but very near to significant ( $p$-value $=0.077$ ). More errors were recorded by those nurses who administered the medication to more than 15 patients. Hence, nurses to patients ratio was also statistically significant with missed drug errors ( $\mathrm{p}$-value $\leq 0.001)$. 
Raja, Badil, Kumar P et al.,

Similarly, the timing of medication administration was also found statistically significant with missed drug errors ( $\mathrm{p} \leq 0.001$ ).

Table-I: Association of Missed Dose Error with Socio-demographic Characteristics of the Participants (n= 204).

\begin{tabular}{|c|c|c|c|c|}
\hline & \multirow[b]{2}{*}{ No Error } & \multicolumn{3}{|c|}{ Missed Dose Error } \\
\hline & & Error & Chi-Square & p-value \\
\hline & $n(\%)$ & $n(\%)$ & & \\
\hline \multicolumn{5}{|l|}{ Age (year) } \\
\hline $25-30$ & $44(50)$ & $44(50)$ & & \\
\hline $31-35$ & $47(58.75)$ & $33(41.25)$ & 4.12 & 0.127 \\
\hline$\geq 36$ & $25(69.44)$ & $11(30.60)$ & & \\
\hline \multicolumn{5}{|l|}{ Gender } \\
\hline Male & $55(51.89)$ & $51(48.11)$ & & \\
\hline Female & $61(62.24)$ & $37(37.76)$ & 2.22 & 0.136 \\
\hline \multicolumn{5}{|l|}{ Education } \\
\hline Diploma in Nursing & $73(54.89)$ & $60(45.11)$ & 0.608 & 0.436 \\
\hline BS. Nursing & $43(60.57)$ & $28(33.43)$ & & \\
\hline \multicolumn{5}{|l|}{ Hospital } \\
\hline Dow University Hospital & $32(68.08)$ & $15(31.92)$ & 3.136 & 0.077 \\
\hline $\begin{array}{c}\text { Dr. Ruth K.M. Pfau Civil } \\
\text { Hospital }\end{array}$ & $84(53.50)$ & $73(46.50)$ & & \\
\hline \multicolumn{5}{|l|}{ Experience } \\
\hline 1- 5 years & $53(54.63)$ & $44(45.37)$ & & \\
\hline $6-10$ years & $26(53.06)$ & $23(46.94)$ & 1.620 & 0.445 \\
\hline$>10$ years & $37(63.80)$ & $21(36.20)$ & & \\
\hline \multicolumn{5}{|l|}{ Working Area (wards) } \\
\hline Surgical ward & $69(59.5)$ & $52(59.1)$ & 0.003 & 0.955 \\
\hline Medical ward & $47(40.5)$ & $36(40.9)$ & & \\
\hline \multicolumn{5}{|l|}{ Patients Ratio } \\
\hline $1-10$ patients & $50(71.42)$ & $20(28.58)$ & & \\
\hline $11-15$ Patients & $36(66.67)$ & $18(33.33)$ & 20.398 & $<0.001^{*}$ \\
\hline$>15$ patients & $30(37.50)$ & $50(62.50)$ & & \\
\hline \multicolumn{5}{|l|}{$\begin{array}{l}\text { Time of Medication } \\
\text { Administered }\end{array}$} \\
\hline $10 \mathrm{am}$ & $70(64.22)$ & $39(35.78)$ & & \\
\hline $2 \mathrm{pm}$ & $32(72.72)$ & $12(27.28)$ & 24.906 & $<0.001^{*}$ \\
\hline $10 \mathrm{pm}$ & $14(27.46)$ & $37(72.54)$ & & \\
\hline
\end{tabular}

*Statistical Significant

\section{DISCUSSION}

Medications hold an important significance in the delivery of healthcare, from the prescription to administration, it is the key aspect in saving patients' lives. Similarly, error in the medication use process may lead to lethal consequences to the patients. However, medication error is a preventable issue, and if controlled can lead to tangible improvements in the delivery of health. Missing medication doses can be detrimental to the hospitalized patients therefore, missed dose errors should be avoided to the maximum ${ }^{[13]}$. In order to control the prevalence of missed dose errors, this study aimed to find out the sociodemographic factors that are associated with missed dose errors.
In this study, the number of male participants was greater $106(52 \%)$ than females.

However, this study could not highlight any significant relationship between gender, age and educational status of the study subjects with missed dose error ( $p$-value $>0.05$ ). Similarly, a study conducted in Iran to find the causes of medication errors did not find a correlation between gender variable and medication errors. Conversely, research study conducted in this regard, have disclosed the importance of nursing education in the improvement of the medication process; and the familiarity of the medical staff to the new techniques and strategies such as electronic cards for patients can assist with error reduction ${ }^{[14]}$.

In current study, a significant relationship was found between the nurse-patients ratio $(\mathrm{p}<0.001)$. Likewise, study 
was conducted to analyze the effect of nurse staffing on the probability of medication errors; the study pointed many influencing factors such as extra work burden, fatigue, patient load, incomplete medication orders that are either damaged or sometimes unreadable, writing of doctors may cause medication errors ${ }^{[15]}$. In addition, another research study revealed that an adequate nurse-patient ratio in a clinical setting significantly decreased the mortality rate by $14 \%$, and adverse events were less likely to happen in the wards ${ }^{[16]}$.

Reducing error, related to missed doses, is an issue that needs to be tackled. There has been several studies conducted on this matter. Research studies have shown several factors which may help to reduce the medication errors such as proper documentation, higher education, self-reporting system, surveillance system and improving medicine distribution system ${ }^{[17,18]}$.

An Iranian study also affirmed that such factors are the common contributors in the phenomenon of medication errors ${ }^{[19]}$. Moreover, communication among the health care personnels is a factor that needs improvement ${ }^{[20]}$.

An Australian study reported a significant improvement of approximately $29 \%$ in the probability of medication errors reduction due to effective and improved communication between the health care workers in the hospital ${ }^{[21]}$. Furthermore, a study of New Zealand demonstrated that nurses' with advanced education led to a decrease in missed dose error by $26.7 \%{ }^{[22]}$ and one more interventional study investigated the impact of nurse education on the incidence of omitted medication doses among hospitalized patients and found a significant reduction of missed doses error after intervention ${ }^{[23]}$. Electronic prescribing can also be an efficient way to decrease missed dose errors ${ }^{[24]}$. In UK, a study explored $8.8 \%$ of improvement in the reduction of missed dose upon the introduction of automation in their prescribing system ${ }^{[25]}$. Hence, health care systems need to take steps to reduce the work burden on nursing practitioner in order to facilitate the smooth and efficient work flow.

\section{CONCLUSION}

Medication administration is a complex process, and missed dose error is a major area to focus on for improving the accuracy of medication administration. The study revealed the frequency of missed dose error and provides opportunities for improvement in nursing practices by elaborating multiple reasons for such types of errors.

\section{limitations:}

Current study has a small sample size so, the research findings cannot be generalized for the whole region. But the concerns regarding missed dose errors and the factors influencing them have been verified and there is indeed the need of other studies to be conducted on this subject in large sample size and on multiple settings.

ACKNOWLEDGEMENT: None.
CONFLICT OF INTEREST: All authors disclose no conflict of interest.

GRANT SUPPORT \& FINANCIAL DISCLOSURE: None.

\section{REFERENCES:}

1. Hammoudi BM, Ismaile S, Abu Yahya O. Factors associated with medication administration errors and why nurses fail to report them. Scandinavian Journal of Caring Sciences. 2018; 32(3):1038-1046. Doi:10.1111/ scs. 12546

2. Ofosu R, Jarrett P. Reducing nurse medicine administration errors. Nursing Times. 2015; 111(20):1214.

3. Al Tehewy M, Fahim H, Gad NI, El Gafary M, Rahman SA. Medication administration errors in a university hospital. Journal of Patient Safety. 2016; 12(1):34-39. Doi: 10.1097/PTS.0000000000000196

4. Feleke SA, Mulatu MA, Yesmaw YS. Medication administration error: magnitude and associated factors among nurses in Ethiopia. BMC Nursing. 2015; 14(1):53. Doi:10.1186/s12912-015-0099-1

5. Salmasi S, Khan TM, Hong YH, Ming LC, Wong TW. Medication errors in the Southeast Asian countries: a systematic review. PloS One. 2015;10(9):e0136545. Doi:10.1371/journal.pone.0136545

6. Taufiq S. Prevalence and Causes of Wrong Time Medication Administration Errors: Experience at a Tertiary Care Hospital in Pakistan. Canadian Journal of Nursing Informatics. 2015; 10(1):1-12

7. Bagheri-Nesami M, Esmaeili R, Tajari M. Intravenous Medication Administration Errors and their Causes in Cardiac Critical Care Units in Iran. Materia SocioMedica. 2015; 27(6):442-446. Doi: 10.5455/msm. 2015.27.442-446

8. Alsulami Z, Conroy S, Choonara I. Medication errors in the Middle East countries: a systematic review of the literature. European Journal of Clinical Pharmacology. 2013; 69(4):995-1008.

9. Raja, Badil, Ali S. Wrong Time Medication Administration Errors and Its Association with Demographic Variables among Nurses in Tertiary Care Hospitals, Karachi. Journal of the Dow University Health Sciences. 2019; 13(1):30-36. Doi:10.36570/ jduhs.2019.1.637

10. Sajjad S, Gowani A, Kazmi A, Mansoor S. Factors Contributing to Medication Errors in a Tertiary Care Private Hospital, Karachi. I-manager's Journal on Nursing. 2017; 7(3):28-35.

11. Ahmed T, Haq N, Ammar M. Assessment of inpatients omission errors made by nurses throughout the medication administration process. MOJ Toxicology. 2018; 4(4):242-245.

12. Ahmed T, Haq N, Minhas M, Iqbal Q, Mehmood $\mathrm{S}$, Waqas $\mathrm{M}$, et al. Medication Administration Errors Evaluation in Pediatric Ward by Pharmacist. International Journal of Biological Sciences. 2017; 4(2):1-6. 
13. National Patient Safety Agency. Reducing harm from omitted and delayed medicines in hospital.2010.

14. Gorgich EA, Barfroshan S, Ghoreishi G, Yaghoobi M. Investigating the causes of medication errors and strategies to prevention of them from nurses and nursing student viewpoint. Global Journal of Health Science. 2016; 8(8):220-227. Doi: 10.5539/gjhs.v8n8p220

15. Mark BA, Belyea M. Nurse staffing and medication errors: Cross-sectional or longitudinal relationships?. Research in Nursing \& Health. 2009;32(1):18-30. Doi:10.1002/nur.20305

16. Driscoll A, Grant MJ, Carroll D, Dalton S, Deaton C, Jones I, et al. The effect of nurse-to-patient ratios on nurse-sensitive patient outcomes in acute specialist units: a systematic review and meta-analysis. European Journal of Cardiovascular Nursing. 2018; 17(1):6-22.

17. Alomar MJ, Ahmad S, Moustafa Y, Alharbi LS. Reducing missed medication doses in intensive care units: A pharmacist-led intervention. Journal of Research in Pharmacy Practice. 2020; 9(1):36-43. Doi: 10.4103/jrpp.JRPP_19_95

18. Morley C, McLeod E, McKenzie D, Ford K, Walsh K, Chalmers L, et al. Reducing dose omission of prescribed medications in the hospital setting: a narrative review. Drugs \& Therapy Perspectives. 2016; 32(5), 203-208. Doi:10.1007/s40267-016-0289-2

19. Shahrokhi A, Ebrahimpour F, Ghodousi A. Factors effective on medication errors: A nursing view. Journal of Research in Pharmacy Practice. 2013; 2(1): 18-23. Doi: 10.4103/2279-042X.114084

20. Choo J, Hutchinson A, Bucknall T. Nurses' role in medication safety. Journal of Nursing Management. 2010; 18(7): 853-861. Doi:10.1111/j.13652834.2010.01164.x

21. Chaboyer W, Johnson J, Hardy L, Gehrke T, Panuwatwanich K. Transforming care strategies and nursing sensitive patient outcomes. Journal of Advanced Nursing. 2010; 66(5):1111-1119.

22. Garratt SM, Kerse NM, Peri K, Jonas MF. Medication omission rates in New Zealand residential aged care homes: a national description. BMC Geriatrics. 2020;20(1):1-8.

23. O'Shea TJ, Spalding AR, Carter FA. Impact of nurse education on the incidence of omitted medication doses in hospital inpatients. Journal of Pharmacy Practice and Research. 2009; 39(2), 114-116. Doi:10.1002/j.2055-2335.2009.tb00433.x

24. Ammenwerth E, Schnell-Inderst P, Machan C, Siebert $\mathrm{U}$. The effect of electronic prescribing on medication errors and adverse drug events: a systematic review. Journal of the American Medical Informatics Association. 2008; 15(5), 585-600.

25. Warrick C, Naik H, Avis S, Fletcher P, Franklin BD, Inwald D. A clinical information system reduces medication errors in paediatric intensive care. Intensive Care Medicine. 2011; 37(4):691-694. Doi:10.1007/ s00134-010-2126-8
Raja: Concieved idea, manuscript writing.

Badil: Proof reading and literature review.

Pawan Kumar: Statistics and analysis of the results.

Sana Rehman: Revised it critically for intellectual content.

Gulsher: Data collection, data compilation.

Submitted for publication: 24-08-2021

Accepted after revision: 02-02-2022 